Aletria, Belo Horizonte, v. 29, n. 3, p. 189-208, 2019

\title{
Estudos literários no Brasil: frestas para uma crítica da experiência
}

\section{Literary Studies in Brazil: Windows for a \\ Critique of Lived Experience}

\section{Ligia Gonçalves Diniz}

Universidade Federal de Minas Gerais (UFMG), Belo Horizonte, Minas Gerais / Brasil ligiadiniz@gmail.com

Resumo: Neste artigo, apresento uma análise de abordagens contemporâneas da crítica literária brasileira, com vistas à abertura do campo a uma abordagem que se centre na experiência afetiva de leitura. A história da teoria e crítica literária brasileira das últimas décadas pode ser contada, em boa parte, pela tensão entre a defesa de uma literatura mimética ou social e uma produção mais voltada à forma e aos "segredos" da linguagem, sobrando pouco espaço para uma leitura de imaginação. Procuro pensar, assim, se a produção acadêmica contemporânea está de alguma forma preocupada, ou abre espaço para se pensar a literatura a partir de seu público real e potencial: leitores não profissionais e leitores em formação.

Palavras-chave: crítica literária; imaginação; leitura; experiência estética.

\begin{abstract}
In this paper, I present an analysis of contemporary approaches to literary criticism in Brazil, aiming to open the field to an approach centred on the affective experience of reading. The history of Brazilian literary studies has been known to oscillate between the defense of a mimetic or socially driven literature and the tendency to praise literary form and the "secrets" of literary language, leaving little room for an approach that centers on the imagination as triggered by fiction and poetry. I aim to look upon the contemporary critic production in search for ways of thinking about literature that have in mind real and potential readers, those that are not professional and that are in training.
\end{abstract}

Keywords: literary criticism; imagination; reading; aesthetic experience. 
Das riquezas demonstráveis de Pasternak (ritmos, métrica etc.) outros terão a chance de falar [...]. Esse é o trabalho dos especialistas em poesia. Minha especialidade é a Vida.

Marina Tsvetaeva

"A discussão constante sobre imaginação e realidade é, acima de tudo, uma discussão não para o uso na vida, mas para as artes e as letras", escreveu Wallace Stevens ${ }^{1}$, em meados do século passado. A razão para isso, dizia ele, é que na vida cotidiana, muito poucas pessoas recorrem à imaginação, enquanto no universo da literatura, poucos recorreriam a qualquer outra coisa. No dia a dia, o que importa é "a verdade como ela é"; já nas artes e letras, "a verdade como a vemos" é o que interessa. Se a diferença é evidente, o poeta faz uma ressalva: por vezes, as pessoas das artes e das letras "recorrem, sem perceber, à realidade" 2 .

A história da crítica literária brasileira das últimas décadas pode ser contada, em boa parte, desde a tensão entre aqueles que recorrem à realidade - sem perceber ou questionar a intensidade com que o fazem - e aqueles que procuram se manter sempre atentos para que não cometam o que seria, aos seus olhos, uma indiscrição. Mais recentemente, entraram em cena também os que recorrem à realidade deliberadamente, e fundem - fazendo dessa fusão sua insígnia - a verdade como ela é e a verdade como a literatura a vê.

Em qualquer caso, esta nossa história é, sobretudo, "a discussão constante sobre imaginação e realidade", em que resta sempre à primeira 0 ônus da prova de sua relevância, já que, quando se lança ao primeiro plano, tem quase sempre o protagonismo roubado pela linguagem, que parece ser um distintivo mais fino de se carregar. Não à toa, neste artigo, veremos o problema ser esboçado de diversos modos e por diferentes pontos de vista, mas sempre se equilibrando sobre a questão da representação na literatura - uma discussão que, no entanto, raramente mergulha na reflexão teórica de fundo, e frequentemente joga para escanteio a relação ente texto e vida que se dá no interior da leitura, experiência que está na origem de todo e qualquer ato crítico.

Procuro delinear o contexto da crítica literária contemporânea, com seus conflitos, anseios e possibilidades, para propor um espaço em

\footnotetext{
${ }^{1}$ STEVENS. Imagination as Value, p. 147, grifos meus.

${ }^{2}$ STEVENS. Imagination as Value, p. 147, grifos meus.
} 
que a imaginação na leitura possa habitar. Busco, assim, o diálogo com trabalhos críticos e teóricos que estejam menos preocupados com a pureza da forma, o valor social, e a rigidez de juízos, do que com a experiência literária e como nela se opera a forma, a partir dela se produz o valor social, e dela se formulam juízos. Se as linhas acima parecem acusatórias, ou, ainda pior, normativas, o intuito não poderia ser mais diverso: longe de pretender criticar esta ou aquela tendência, meu objetivo é propor que, atravessando todas elas, sempre há um leitor por trás do crítico literário, e que é vital ouvir o que esse leitor tem a dizer.

Assim, inicio o artigo esboçando uma proposta de um críticoleitor, subvertendo a pesquisa de Leyla Perrone-Moisés sobre o que denomina "escritores-críticos" e tentando alargar a proposta de "críticospoetas" de Alberto Pucheu, para depois traçar um breve panorama do contexto dos estudos literários hoje - no qual ficará clara a dicotomia sempre renovada e repetidamente problematizada entre linguagem e realidade - e, então, tentar encontrar um espaço em que outras vozes que emergem possam interagir e se movimentar.

\section{A articulação da experiência e o crítico-leitor}

Para Leyla Perrone-Moisés, o século XX procurou abalar a certeza sobre a natureza judicativa da crítica literária, sem conseguir derrubá-la. Segundo a autora, no esforço por uma menor subjetividade, a crítica universitária tornou-se cada vez mais analítica, querendo se impor como "científica" e se esforçando por deixar de lado avaliações de valor explícitas, acusadas de manifestações de gosto pessoal. Perrone-Moisés observa que se trata de um empenho, em última medida, vão, já que, sempre que se faz um discurso sobre uma obra literária, não há como evitar o exercício de uma apreciação, mesmo que esta esteja implícita na simples escolha de um texto, e não outro, como objeto de crítica. Ela então afirma, tomando-os como objeto de pesquisa, que são os autores literários aqueles que, por não precisarem de outro tipo de legitimação, produzem uma obra crítica que quebra essa tendência contraditória, lida "diretamente com os valores e exerce, sem pudores, a faculdade de julgar"3.

Perrone-Moisés lembra que, quando atuam como críticos os escritores se encontram, primeiramente, na posição de leitores - não

\footnotetext{
${ }^{3}$ PERRONE-MOISÉS. Altas literaturas, p. 10-11.
} 
apenas no sentido trivial, mas em uma abordagem contemporânea que vê na leitura, em vez de um processo que desvela "o que a obra contém, em sua verdade essencial", uma experiência que "literalmente recria a obra". Como críticos que, por sua posição privilegiada, contribuem para uma construção da história literária, esses escritores, na qualidade de leitores anônimos ou comuns, respondem ao texto, mas também, principalmente, têm "a capacidade de articular essa resposta"4.

Não cabe aqui entrar no problema do acesso ao campo literário, mas reivindicar, para nós, críticos e teóricos comuns, as alegrias e dificuldades de uma produção que não precise pagar tantos pedágios para se afirmar legítima: apenas - e não é pouco - ter a "capacidade de articular essa resposta" ao texto literário. Teríamos assim, a passagem dos escritorescríticos aos críticos-leitores, que, munidos de referenciais teóricos, sociais, históricos os mais variados, porém não reféns deles, dariam vida à vocação dos estudos literários de ocupar, por seu acesso à experiência humana, um lugar menos cerceado e fraturado, o que não pressupõe, é claro, um território pacífico.

Alberto Pucheu começa um de seus ensaios dedicados a pensar nosso campo de trabalho dizendo, um tanto exageradamente, que jamais ouviu "alguém dizer que sentiu as palavras de um crítico literário brasileiro lhe tocarem a alma, o coração ou os nervos"s. Pucheu insiste que os estudos literários - mais especificamente, no que tange à crítica de poesia-demandam, por sua condição de "pensamento da encruzilhada ou da permeabilidade", uma dicção mais poética, cuja intensidade não se vem deixando assomar ${ }^{6}$. Ecoando a denúncia da dissimulação de uma crítica que se quer objetiva quando desde sempre já fala de dentro do "campo de forças de onde eclode seu desejo", ele aponta que

a crítica literária habitual classifica, esquematiza, sistematiza, codifica, cataloga, parafraseia, descreve, analisa, demonstra, explica, hierarquiza, busca as fontes, mostra as fases de evolução, organiza pelas semelhanças, uniformiza, arquiva, ficha, clarifica, oferece dados cronológicos biográficos ou bibliográficos desconhecidos do público, compara, salienta o fundamento ideológico, revê a fortuna crítica, assinala

\footnotetext{
${ }^{4}$ PERRONE-MOISÉS. Altas literaturas, p. 13-14.

${ }^{5}$ PUCHEU. Pelo colorido, para além do cinzento, p. 11.

${ }^{6}$ PUCHEU. Pelo colorido, para além do cinzento, p. 12-13.
} 
as influências recebidas, demarca a genealogia livresca de certos temas, $[\ldots]$ etc. etc. etc. ${ }^{7}$

Pucheu retoma uma afirmação de Antonio Candido, para quem "a crítica é cinzenta, e verdejante o áureo texto que ela aborda", para falar de seu desejo de liberar a crítica "de seus escrúpulos cinzentos, da gentlemania excessiva de quem até poderia avocar sua escrita como colorida, mas não o faz, mantendo fixa a faixa de segregação entre literatura e crítica"s. Mais recentemente, em uma "tese sobre a crítica literária brasileira", Pucheu volta a apontar a miopia da crítica na percepção sobre seu lugar, com a permanência de um desejo de objetivismo e de "um princípio de aplicabilidade", que supõem "o poético como autônomo e exclusivo" e a crítica, como secundária 9 . Entre os autores em que ele observa esse descompasso está Silviano Santiago, ele próprio um autor de ficção e poesia, para quem o trabalho crítico "sempre vem a reboque" das obras e tendências literárias. A expressão é do próprio Santiago, em Uma literatura nos trópicos, cuja nota prévia à edição de 2000 traz ainda a noção de crítico como "intérprete", que tem por tarefa "colocar as ideias no devido lugar", o que significa nada menos que deixar que o leitor "encontre trampolins menos intuitivos para o salto de leitura"10.

Não compartilho a ideia de Pucheu de que só é "colorido" o texto em alguma medida poético ou literário, o que me parece abrir as portas para uma enxurrada de páginas kitsch sob o afã da renovação da linguagem crítica. Gostaria, porém, de instaurar sob esse mesmo "colorido" uma crítica que não tenha medo de deixar emergir uma subjetividade da experiência, a qual é hoje, ainda, tabu. Mesmo se pensarmos no crítico como um mediador - a mediação pensada como uma apresentação, um gesto em que o crítico fala de um lugar específico, não o de uma autoridade sem corpo -, é preciso lembrar que, no extremo da comoção da leitura, o texto não nos dá, como diz ainda Pucheu, "chance a exegeses, bloqueando, momentaneamente, nossa possibilidade de falar alguma coisa dele, obrigando-nos a relê-lo, a ficar exclusiva e

\footnotetext{
${ }^{7}$ PUCHEU. Pelo colorido, para além do cinzento, p. 13.

${ }^{8}$ PUCHEU. Pelo colorido, para além do cinzento, p. 14-15. O trecho original de Candido está em um dos ensaios de $O$ albatroz e o chinês.

${ }^{9}$ PUCHEU. Uma tese sobre a crítica literária brasileira (por uma crítica poética), p. 158. ${ }^{10}$ SANTIAGO. Uma literatura nos trópicos, p. 7.
} 
exaustivamente com ele, [...] a querer passá-lo adiante tal qual ele é"11. Transformar esse "susto" em escrita exige "tornar-se livre para, com a violência sofrida, esbarrar em outros corpos". "Entulhamento" de interpretações e "parasitismo" em relação à obra, são, para ele, os dois dilemas que mostram a crise dos estudos literários ${ }^{12}$. Pucheu soma, ainda, à crítica poética, como antídoto à mesmice, a possibilidade de uma crítica filosófica, que procura preservar a complexidade, ambiguidade e resistência última da obra à apreensão total.

\section{Linguagem e mundo}

A questão que fica é: como preservar o que a obra tem de inapreensível, se a tradição brasileira parece se mover em uma disputa sobre formas de apropriação do literário? Leda Tenório da Motta é uma das vozes que apontam o fato de que uma querela entre determinismos sócio-históricos e liberdades da forma está ainda na base do que move o nosso campo. De um lado, ela apresenta os herdeiros de Antonio Candido, capitaneados por Roberto Schwarz, e, de outro, os críticospoetas, de que é referência Haroldo de Campos: de um lado, o pensamento crítico que surgiu nos anos 1950, "da aclimatação difícil de nossas produções literárias, objetos sempre, de algum modo, deslocados, e progressivamente conscientes disso"; de outro, "o da devoração sem culpa, sob a culta, estrangeira e alegre influência""13.

No primeiro caso, Motta destaca a influência de "sociologias da arte", que, apesar de alguns acertos, redunda em uma obra, geralmente, "sem grande voo interpretativo" e dedicada a, frequentemente, enxergar o literário como apenas um reflexo do social, mesmo que revestido de ou tornado forma estética ${ }^{14}$. No segundo caso, o de Haroldo de Campos e sua "poética sincrônica", vemos o que ele próprio defendia como uma retificação dos julgamentos errôneos da "poética histórica", agora com rigor estético e sem interesse por valores sociológicos ${ }^{15}$. A veemência da tensão entre os dois lados se revestiu, por vezes, entre os concretistas,

\footnotetext{
${ }^{11}$ PUCHEU. Pelo colorido, para além do cinzento, p. 19-23.

${ }^{12}$ PUCHEU. Dois críticos, para que servem?, p. 79-80.

${ }^{13}$ MOTTA. Sobre a crítica literária brasileira no último meio século, p. 54.

${ }^{14}$ MOTTA. Sobre a crítica literária brasileira no último meio século, p. 14.

${ }^{15}$ CAMPOS. Por uma poética sincrônica, p. 207.
} 
de um ataque à teoria simplesmente, como quando Augusto de Campos, na introdução à segunda edição da Teoria da poesia concreta, de 1975, defendeu que a "teoria não passa de um tacape de emergência a que o poeta se vê obrigado a recorrer, ante a incompetência dos críticos"16.

Passando ao outro extremo, é difícil discordar de Maria Elisa Cevasco, herdeira intelectual de Schwarz, quando diz que o modo como este "lê literatura redefine a prática da crítica literária entre nós" 17 - para o bem ou para o mal, conforme o ponto de vista. Schwarz não é a única influência de uma vertente crítica que, ainda hoje, reafirma que "a forma artística é uma síntese que nos possibilita uma compreensão intuitiva do todo social". Não é, aliás, descabido afirmar, sobre ele e Antonio Candido, que abriram as portas, no Brasil, para os estudos culturais de hoje. Tanto é que, longe das trincheiras acadêmicas nacionais - em obras sobre os estudos culturais latino-americanos publicadas no exterior, por exemplo -, Candido aparece como precursor, enquanto Schwarz é apresentado como fundador dessa tendência crítica no Brasil ${ }^{18}$.

Contemporâneo de Schwarz, Alfredo Bosi tem um lugar ligeiramente deslocado em relação à matriz do materialismo dialético da USP: enquanto os dois compartilham "o cuidado de aproximar a forma literária das tensões sociais que a atravessam" - com reservas, portanto, quanto às abordagens mais formalistas -, Bosi afirma que diverge quanto à, talvez, principal tese de Schwarz: a de que a literatura brasileira se estabeleceu sobre "ideias fora do lugar", isto é, ideias vindas da Europa que, aqui não podendo deixar de penetrar, eram "usadas sempre em sentido impróprio" 19 . Além disso, na obra de Bosi, há uma constante de rejeição à ideia de obra como reprodução mimética da sociedade, nota que valerá para as ressalvas que fará sobre a obra de Schwarz e de Candido.

Talvez por isso Bosi não seja, como os outros autores da escola materialista, enxergado como precursor dos estudos culturais. Ele, aliás, já declarou ver nestes uma resposta "com ênfase e radicalismo simétricos e opostos" ao estruturalismo, que imperou nos anos 1960 e 70 e foi responsável por encerrar o texto em si próprio, "sem janelas para o contexto

\footnotetext{
${ }^{16}$ CAMPOS. Introdução à 2a edição de Teoria da poesia concreta, p. 13.

${ }^{17}$ CEVASCO. Formas trabalhando formas, p. 265.

${ }^{18}$ Ver, por exemplo: MOREIRAS, The Exhaustion of Difference; e DEL SARTO; RÍOS; TRIGO, The Latin American Cultural Studies Reader.

${ }^{19}$ BOSI. Entrevista sobre crítica literária, p. 311. Ver SCHWARZ. As ideias fora do lugar.
} 
e para o sujeito" 20 . Como resultado, diz ele, observa-se a "tentação de fazer um novo e às vezes tosco sociologismo", banindo o termo "estético" dos debates sobre a natureza da literatura.

De fato, a energia mobilizada pela crítica de viés sócio-histórico só rivaliza, se tanto, com as angústias pós-estruturalistas, que se mantêm centradas no texto, discorrendo sobre as aporias na relação entre literatura e realidade. Estou adotando, sem dúvida, um tom excessivamente generalizante, que não dá conta das frestas por onde o texto respira na teoria e na crítica atuais - frestas, aliás, que, se não existissem, não me permitiriam reivindicar uma crítica centrada na experiência de leitura. Ainda assim, é difícil não se incomodar com parte da crítica desconstrutivista e pós-estruturalista que tem no apuro da linguagem teórica e ensaística uma importância que por vezes excede a do debate de ideias e do compartilhamento de afetos.

Por todos esses motivos, não é simples vislumbrar uma tendência inequívoca nos estudos literários. Para João Cezar de Castro Rocha, a única certeza é de que hoje se produz apenas um confronto de monólogos, o que redunda em um clima de "marasmo", isto é, o "sentimento de que as teorias revolucionárias já foram elaboradas, assim como já foram escritos os romances e poemas transformadores" - sentimento que é acompanhado de e provocado, também, pela força da "indústria cultural", que relega a literatura a um papel periférico. Ao marasmo junta-se o que o autor chama de epigonia dos estudos literários brasileiros: estamos sempre imitando ou prolongando uma tradição, esta sim, em seu tempo, inovadora ${ }^{21}$.

Castro Rocha afirma que "o marasmo principiou a tomar conta da vida cultural brasileira a partir do momento em que os grupos endogâmicos deixaram de dialogar com interpretações concorrentes", o que matou a polêmica, que sempre havia funcionado como motor da vida intelectual. Ele não expressa, contudo, se é possível promover um diálogo polêmico que não se centre em diferentes versões da boa e velha tensão entre os estudos preocupados com a relação da forma com o processo social e as análises dedicadas à experiência com a própria linguagem.

A dificuldade em matar o pai acadêmico - qualquer que seja ele - fica evidente, porém, no pensamento do próprio Castro Rocha. Em artigo posterior, o autor propõe que, para escaparmos ao eterno retorno às

${ }^{20}$ BOSI. Entrevista sobre crítica literária, p. 309.

${ }^{21}$ ROCHA. Crítica literária: em busca do tempo perdido?, p. 115-116. 
disputas do século passado, é imperativo reler aqueles mesmos "debates e alcançar certo nível de consenso que permitisse considerar quais são os problemas críticos efetivamente resolvidos". Ele afirma, então, que, após Schwarz, é imperativo "reconhecer de maneira inequívoca a forma propriamente machadiana de lidar com a circunstância histórica do Brasil escravocrata. E ponto final" ${ }^{22}$. Castro Rocha afirma ainda que, depois que "os irmãos Haroldo e Augusto de Campos e Décio Pignatari assumiram a tarefa de reavaliar o legado de Oswald de Andrade", resolveu-se "efetivamente esse problema crítico".

Talvez por crer que problemas centrais já estejam "resolvidos", Castro Rocha entende que, hoje, a literatura ocupa posição periférica no quadro cultural. A partir daí, defende que essa condição "suplementar" é fecunda, uma vez que "libertou' a literatura do incômodo papel de testemunho da nacionalidade", na mesma medida em que "o questionamento de certos pressupostos teóricos [...] libertou a literatura da obrigação de revelar [...] o eterno retorno da literariedade" ${ }^{23}$. Nessa situação, o autor propõe que críticos acadêmicos exerçam uma "esquizofrenia produtiva", aprendendo a dialogar com seus pares tanto quanto com um público mais amplo.

Soa estranho que a "esquizofrenia produtiva" defendida por Castro Rocha, com todo o seu caráter de flexibilidade, não encontre, para ele, uma contrapartida nos departamentos universitários, nos quais, ele defende, deve haver fidelidade à prática estritamente literária. Rocha critica os professores de Letras "cada vez mais preocupados em exibir dotes filosóficos, discutir os últimos lançamentos cinematográficos, além de ensaiar análises musicais" - o que evidenciaria a formação de "uma cátedra cada vez menos interessada no estudo da literatura" ${ }^{24}$. Em outras palavras, exige-se que o leitor (sempre multifacetado) restrinja sua experiência a um domínio específico, sob pena de escapar ao literário. Embora se apresse em contemporizar o sarcasmo da avaliação, elogiando "a versatilidade, talento relevante nos dias que correm" e "a transdisciplinaridade, pois, afinal, nenhum discurso é mais onívoro do que o literário", o autor logo propõe que, para exercer tal versatilidade e

\footnotetext{
${ }^{22}$ ROCHA. Considerações sobre a crítica literária, p. 38-39.

${ }^{23}$ ROCHA. Crítica literária: em busca do tempo perdido?, p. 379.

${ }^{24}$ ROCHA. Crítica literária: em busca do tempo perdido?, p. 351-352.
} 
transdisciplinaridade, os professores deveriam "iluminar seus pares nas respectivas Faculdades de Filosofia, Cinema e Música”.

$\mathrm{O}$ alvo da troça de Castro Rocha é, salvo engano, os estudos culturais. É também essa vertente crítica que o autor entende mais responsável pela tendência de endogamia acadêmica, relação que ele observa com mais cuidado no artigo de 2014, no qual afirma que diferentemente do que acontecia até os anos 1980, professores que adotam essa perspectiva não precisam mais debater com os adversários para legitimar sua opção "porque as condições novas de institucionalização da universidade brasileira permitem uma circulação plena de seus trabalhos no interior do mesmo grupo" 25 .

A polêmica em torno dos estudos culturais - e das condições literárias e sociais em que se inserem - vai longe e envolve boa parte dos nomes mais consagrados da crítica nacional, desde Bosi, como já vimos, até o jornalista Sergio Rodrigues, um dos mais conhecidos representantes hoje da crítica literária não acadêmica. Alcir Pécora, por exemplo, escreve que, pela perspectiva da literatura a partir da representação social, aquela passa "a importar como lugar de defesa de identidades de grupos, especialmente aqueles com menos direitos assegurados no âmbito da sociedade de orientação democrática", sendo, inteira "repensada como testemunho, quer dizer, como depoimento pessoal, mas também social" 26 . No ensaio, emblematicamente intitulado "A musa falida", Pécora vê na emergência dos estudos culturais "um sinal contundente da natureza da crise contemporânea da literatura". A argumentação para tanto resvala em um purismo estético que parece se confundir com desejo de desobrigação ética: "É preciso perder as ilusões a esse respeito: a literatura perdeu definitivamente a velha isenção metafísica que a supunha acima do jogo sujo"27.

O ensaio parece uma retratação parcial de artigo polêmico, de 2011, em que ele tratava de "um vírus da irrelevância" que atingia a literatura no Brasil, manifesto principalmente por uma grande produção de "literatura mediana", que "não serve para nada", porque lhe falta a techné da produção objetiva ${ }^{28}$. Quais seriam, nesse contexto, o papel, a responsabilidade e as possibilidades dos estudos literários no interior da

\footnotetext{
${ }^{25}$ ROCHA. Considerações sobre a crítica literária, p. 35.

${ }^{26}$ PÉCORA. A musa falida, p. 49.

${ }^{27}$ PÉCORA. A musa falida, p. 50.

${ }^{28}$ PÉCORA. Impasses da literatura contemporânea.
} 
academia? Para Flora Süssekind, "[t]alvez" seja de um "'lugar estreito demais', e pouco público, desse ponto cego que talvez não se veja em jornais e nas manifestações mais concorridas da vida literária, que caiba à crítica e à literatura definir outros espaços de atuação e trânsito"29. Tal ponderação aparece em um ensaio que deu início a um outro quiproquó, já lendário, do campo literário.

A querela partiu da acusação de um "ressentimento nostálgico, e certo proselitismo agressivamente conservador" que, para ela, haviam dominado os necrológios do crítico e historiador literário Wilson Martins. Os elogios de autores como Alcir Pécora, Sérgio Rodrigues e Miguel Sanches Neto a Martins apontariam, segundo Süssekind, para "o apequenamento e a perda de conteúdo significativo da discussão crítica" e uma recusa à entrada de vozes externas ao espaço estritamente literário, em uma "inequívoca vontade de retorno a [...] um regime estável e hierarquizado de vozes e gêneros, a regras fixas de apreciação e prática textual, a um apagamento de novos espaços de legibilidade" ${ }^{30}$.

Em sua resposta, Sérgio Rodrigues afirma que Süssekind não percebe que "o grande elemento faltante nesse ambiente, a crítica universitária de fôlego que ela própria representa, retirou-se do debate porque quis", isto é, vem se esquivando de tratar da literatura contemporânea, e se voltando para outras manifestações artísticas ${ }^{31}$. Para Rodrigues, a causa da "birra" de Süssekind é a "progressiva hegemonia dos chamados estudos culturais", cuja "predominância transformou em truísmo a idéia de que a literatura como a conhecemos é apenas um instrumento de dominação de classe". A birra com os estudos culturais certamente dá o tom da resposta do próprio autor, que se aflige: "Escrever 'mal', ser incapaz de construir um personagem, reinventar a pólvora modernista, aborrecer o leitor desavisado, tudo isso é considerado preferível a ser mais um a perpetuar aquele jogo ideológico chamado literatura". Mas a saída, para ele, parece ser que os críticos acadêmicos entrem, ou entrem de vez, "na tal roda de festivais, prêmios, blogs, oficinas etc.". Resistir a essa roda, diz ele, mostra que "a boa crítica universitária" é "vítima de escolhas que [...] ameaçam encurralá-la num beco sem saída de autismo e irrelevância".

\footnotetext{
${ }^{29}$ SÜSSEKIND. A crítica como papel de bala, p. 305.

${ }^{30}$ SÜSSEKIND. A crítica como papel de bala, p. 301.

${ }^{31}$ RODRIGUES. A crítica de mal com a literatura.
} 
É um pouco assustadora, e bastante preguiçosa, a ideia de que é preciso sair da universidade para que a crítica possa acompanhar o espírito do tempo e conquistar relevância. Karl Erik Schollhammer, por exemplo, vem buscando, na academia, o "próprio da literatura" em contraposição à força contemporânea do audiovisual. "Não é mais possível ler contos ou romances sem considerar a interferência que têm sobre a leitura [...] os meios audiovisuais", ele escreve, para concluir, mais adiante, que a "própria literatura contemporânea é fascinada pela imagem, refere-se insistentemente ao universo visual" 32 .

Schollhammer desenvolve o conceito de "realismo afetivo", a partir do que identifica como um interesse renovado da literatura pela questão do realismo: "Entre os escritores contemporâneos percebemos a mesma reciclagem de formas literárias com uma aproximação determinada à 'realidade' da experiência comum", em "uma estranha combinação entre representação e não representação", visível "na atenção em relação à literatura em sua capacidade de intervir na realidade receptiva e de agenciar experiências perceptivas, afetivas e performáticas" ${ }^{33}$. Independentemente de suas conclusões, é importante notar o mérito de Schollhammer em partir dos mesmos "problemas" identificados por críticos como Süssekind ou Pécora - a espetacularização da literatura; a imposição do real - e pensar sobre como as formas literárias contemporâneas absorvem esses riscos, e como a crítica pode lidar com eles.

Vale questionar, assim, por que, se claramente não dominam o campo, os estudos culturais possuem uma força tão incômoda. Há, em primeiro lugar, a potência de um grupo unido - o que, para seus críticos, constitui um "autopúblico" -, que atrai muitos novos estudantes e pesquisadores pela possibilidade de trabalhar com literatura e, ao mesmo tempo, atuar politicamente. Como defende apaixonadamente Beatriz Resende, os estudos culturais oferecem "a possibilidade de politização - no sentido grandioso que a palavra deve ter - da investigação intelectual proposta" 34 .

\footnotetext{
${ }^{32}$ SCHOLLHAMMER. Além do visível, p. 7.

${ }^{33}$ SCHOLLHAMMER. Realismo afetivo, p. 129-130.

${ }^{34}$ RESENDE. Estudos literários, estudos nacionais, estudos culturais.
} 


\section{Uma crítica feita de possibilidades}

Todas essas questões reverberam no outro lado da crítica literária, o dos leitores "comuns". Assim, a leitura de literatura, é pensada, no Brasil, em boa parte das vezes, em extremos. De um lado, a submersão quase mística na linguagem, "ritual" a que só têm acesso iniciados. De outro, aqueles que se dedicam a pensar a literatura por sua influência sobre a sociedade ou como documento das desigualdades socioeconômicas e culturais e que não pensam o leitor senão como sujeito ou ator sociais. Entre um e outro, ou alheia aos dois, fica a preocupação com a formação de novos leitores, levada a cabo especialmente no contexto do ensino de literatura, que restringe a discussão a uma outra situação muito específica de contato com o texto literário - privilegiando agora a reflexão sobre políticas e práticas sociais, sobre escolhas de textos, modo de avaliação etc., em detrimento da experiência estética singular, que tem na linguagem um de seus eixos de apoio.

Além disso, os pesquisadores e críticos universitários parecem, em muitos momentos, ignorar que, para se ensinar literatura na escola, é preciso pensar a literatura, e que esse pensamento tem que se dar no interior da licenciatura em Letras, onde muitas vezes estamos também formando leitores, pelo exercício da aproximação do texto feita do compartilhamento da experiência literária. Se não tivermos isso em mente, manteremos a lacuna existente entre os estudantes que se voltam à pesquisa que se quer mais sofisticada e aqueles que se preparam para o ensino escolar. Perdem os dois lados: um por se ensimesmar em um universo em que se esquece que é preciso haver outros leitores que não os profissionais; o segundo por ir para a sala de aula sem saber como reunir em uma só prática as reflexões teóricas das (parcas) aulas de teoria literária do currículo e as pouquíssimo sofisticadas lições da pedagogia. Há alguns anos, Luiz Costa Lima já acusava o problema dos currículos de licenciatura em Letras:

Basta-me [...] chamar a atenção para o próprio realce do pedagógico em um leque curricular, ao mesmo tempo, fragmentado e restrito. Fragmentado, basicamente, pela divisão esquizo entre teoria e literatura brasileira. A distinção em si já é ridícula, pois não pode haver teoria sem operacionalização, que, no caso, seria fornecida pela intensa leitura anterior do objeto literário, nem pode haver 
estudo de alguma literatura sem algum embasamento teórico. [...] o curso de letras não sabe o que fazer com a reflexão teórica e os ditos teóricos da literatura não sabem o que fazer com seu objeto. ${ }^{35}$

Costa Lima certamente é um caso à parte nas polarizações da crítica no Brasil. Sua batalha é contra as próprias dificuldades em produzir teoria e crítica por aqui, o que se converte muitas vezes em lamento: "Não sabemos sequer a quantos leitores poderá interessar a reflexão em torno de um objeto em baixa, a 'literatura'”, escreve ele ${ }^{36}$. Na introdução à edição original de Mímesis: desafio ao pensamento, de 2001, o autor já afirmava que é "raro encontrar em um crítico (de arte ou de literatura) a indagação do que ele precisamente faz. Como se a crítica por si se autolegitimasse". A questão de fundo - "como justificar a crítica a um objeto de arte" - seria totalmente "descartada pela resposta "sociológica"" 37 .

Penso que os departamentos de Letras, e em particular os de literatura, só têm a ganhar assumindo o papel de uma espécie de domínio geral das humanidades - em que o pensamento teórico, ao lado do criativo, é essencial -, tomando para si uma prática filosófica como que freestyle ${ }^{38}$ e, para usar o clichê, desenvolvendo uma atividade antropofágica-o que, em nenhum dos casos, quer dizer selvagem ou aproxima a área de um terreno de vale-tudo. Se o perigo da negligência ao texto literário parece latente, e às vezes explícito, no interior de muitas discussões acadêmicas, não é menos verdade que o qualitativo "literário" é muitas vezes restrito de tal forma que só beneficia quem está preocupado com o próprio lugar institucional. Não me refiro, portanto, quando temo por sua negligência, apenas à literariedade dos textos - esse fantasma -, mas à literariedade das próprias discussões, isto é, ao que faz delas pertinentes aos estudos literários, e não às ciências sociais, à filosofia ou às outras artes. Além disso, sob qualquer critério, o literário tem suas fronteiras cada vez mais problemáticas, e problematizadas.

\footnotetext{
${ }^{35}$ LIMA. A praga do beletrismo, p. 2.

${ }^{36}$ LIMA. Frestas, p. 24.

${ }^{37}$ LIMA. Mímesis, p. 25.

${ }^{38}$ Empresto o termo às modalidades de dança ou de rap, em que é valorizada a improvisação, e onde há uma espécie de desestrutura estruturada e uma intuição coreográfica que dá forma aos movimentos.
} 
Com o receio de propor uma crítica literária fragmentada, que colhe uma ideia aqui e uma citação acolá, apressei-me, acima, a defender o que chamei de "humanidades freestyle" de uma possível acusação de selvageria. Agora volto atrás, para dizer que também a selvageria intelectual, desde que produtiva, pode ter a sua hora, precisamente porque, para acreditarmos no futuro do nosso campo, é preciso acreditar que há questões a serem inventadas - e inventá-las.

Talvez, por isso, tão importante quanto defender que grupos discordantes mantenham diálogo entre si, seja a valorização de uma autonomia crítica, e mesmo teórica, individual. A filiação a esta ou àquela corrente por vezes tende à aplicação de modelos menos ou mais generosos a diferentes textos literários, o que sequestra do crítico sua porção leitor: mais do que subjetiva, sua porção afetiva. Sob o mote da selvageria, proponho como modo de revitalização da crítica literária uma apropriação da obra menos circunscrita a conceitos. Não estou falando de uma crítica que se orgulhe de ser "impressionista" ou "diletante", para usar os adjetivos proibidos à especialização universitária, e sim de uma produção que parta da leitura da obra rumo aos conceitos ou enquadramentos que mais se apliquem à experiência. Proponho uma produção que aproxime seu leitor do texto literário pelo gesto de compartilhamento de experiência. Se essa proposta pode soar selvagem, justifico-me dizendo que, sem certa dose de indocilidade e de indisciplina, nos campos da literatura pouco se inventa.

Concordo, portanto, com Alexandre Nodari quando afirma que a tão lamentada crise das humanidades se insere em um cenário mais amplo de falta de perspectivas animadoras, que tem em uma de suas frentes um projeto humanista que insiste na "divisão natureza e cultura, projeto que se revela ecológica e mesmo humanamente insustentável". Nesse contexto, talvez a única saída seja investir na literatura à maneira proposta pelo autor: como uma antropologia "especulativa, isto é, imaginária, mas não menos real por isso, pois depende de o ser situar-se como se fosse outro: o sujeito como se fosse objeto, o possível como se fosse atual, o inexistente como se fosse existente". Por esse processo, a ficção designaria o encontro "entre modos - entre atual e possível, existente e inexistente", em que o "entrecruzamento entre eu e outro é real e existe" e "designa uma via recíproca, de mão dupla, uma ponte entre mundos, em que tanto a identidade quanto a diferença se afirmam ao mesmo tempo e se reconfiguram mutuamente" 39 .

\footnotetext{
${ }^{39}$ NODARI. A literatura como antropologia especulativa, p. 77.
} 
Mas o que isso tem a ver com a crise das humanidades ou as possibilidades da crítica e da teoria literárias? A partir de uma ideia do virtual - emblemática da contemporaneidade sempre on-line - como "o lugar onde a existência é possível no duplo sentido" e onde "a existência se dá no modo da possibilidade", o autor questiona se o enfraquecimento da importância institucional das humanidades não se deve precisamente ao fato de elas se dedicarem à "tentativa de colocar a imaginação no poder, potencializar a imaginação". Entre os críticos e teóricos ligados aos departamentos de Literatura brasileiros atuais, Nodari emergiu entre as leituras que informam este artigo como alguém que enxerga com energia a potência que nosso campo guarda e que tem a ver com a própria experiência da leitura.

No entanto, se nele essa visão se explicita, isso não quer dizer que essa espécie de resistência não apareça, menos ou mais explicitamente, em muito do que se vem produzindo recentemente. Anderson da Mata vem realizando leituras de autores contemporâneos centrada nos efeitos sobre o leitor, seja por meio dos incômodos entendidos como afetos intrínsecos à experiência da leitura da obra de João Gilberto Noll ${ }^{40} \mathrm{ou}$, em outro exemplo, na noção de transfiguração defendida na leitura de Silviano Santiago ${ }^{41}$.

Rosana Kohl Bines é outro nome que surge ao se pensar em literatura como locus de movimento de corpo/consciência do leitor (disparada por narradores, personagens), seja em suas leituras de Samuel Rawet $^{42}$ ou de reflexões sobre o imaginário ${ }^{43}$. A mobilização afetiva do crítico-leitor fica aparente, para citar exemplo recente, em diversos artigos de dossiê sobre o tema leitura como experiência, publicados na revista Estudos de Literatura Brasileira Contemporânea ${ }^{44}$, destacandose os textos em que Lia Duarte da Mota aborda o comprometimento do corpo do leitor em romance de Elvira Vigna ${ }^{45}$ e em que Ricardo Augusto de Lima faz um exercício do deslocamento de si enquanto sujeito leitor

\footnotetext{
${ }^{40}$ MATA. Ficções.

${ }^{41}$ MOTA. Uma poética da ferida aberta.

${ }^{42}$ BINES. Por que não fechar os livros de Rawet?

${ }^{43}$ BINES. Assombrações da infância com Boltanski e Benjamin.

${ }^{44}$ DINIZ.; NAKAGOME. Dossiê Leitura e Experiência.

${ }^{45}$ MOTA. Um corpo de leitura.
} 
da autoficção de Tiago Ferro ${ }^{46}$. Quero acreditar, portanto, que a porção experiencial da crítica e da teoria literárias - o crítico como leitor, afetado pelo texto - talvez irrompa em uma nova geração de pesquisadores.

\section{Referências}

AUGUSTO de Lima, R. Autoficção e experiência em O pai da menina morta, de Tiago Ferro. Estudos de Literatura Brasileira Contemporânea, v. 57, p. 1-14, 2019.

BINES, Rosana Kohl. Assombrações da infância com Boltanski e Benjamin. Alea: Estudos Neolatinos, v. 17, p. 227-245, 2015. Doi: https:// doi.org/10.1590/1517-106X/172-227.

BINES, Rosana Kohl. Por que não fechar os livros de Rawet?. In: BINES, Rosana Kohl; CHIARELLI, Stefania; MATA, Anderson da. (org.). Rawet em Diálogo. Campinas: Pontes, 2019, p. 15-38.

BOSI, Alfredo. Entrevista sobre crítica literária. In: CORDEIRO, Sergio et al. (org.). A crítica literária brasileira em perspectiva. Cotia: Ateliê Editorial, 2013, p. 307-314.

CAMPOS, Augusto de. Introdução à 2. ed. In: CAMPOS, Augusto de; PIGNATARI, Décio; CAMPOS, Haroldo de. Teoria da poesia concreta: textos críticos e manifestos 1950-1960. Cotia: Ateliê Editorial, 2006, p. 13-18.

CAMPOS, Haroldo de. Por uma poética sincrônica. A arte no horizonte do provável. 4. ed. São Paulo: Perspectiva, 1977, p. 205-224.

CEVASCO, Maria Elisa. Formas trabalhando formas: a crítica literária segundo Roberto Schwarz. In: CORDEIRO, Sergio et al. (org.). A crítica literária brasileira em perspectiva. Cotia: Ateliê Editorial, 2013, p. 265298.

DEL SARTO, Ana; RÍOS, Alicia; TRIGO, Abril (org.). The Latin American Cultural Studies Reader. Durham, London: Duke University Press, 2004.

\footnotetext{
${ }^{46}$ AUGUSTO de LIMA. Autoficção e experiência em O pai da menina morta, de Tiago Ferro.
} 
DINIZ, Ligia G.; NAKAGOME, Patricia (org.). Dossiê Leitura e Experiência. Estudos de Literatura Brasileira Contemporânea, n. 57, p. 1-9, 2019. Doi: https://doi.org/10.1590/2316-4018571.

LIMA, Luiz Costa. A praga do beletrismo. Eutomia, v. 1, n. 4, p. 1-9, 2009. Disponível em: http://www.repositorios.ufpe.br/revistas/index.php/ EUTOMIA/article/view/1805/pdf. Acesso em: 4 mar. 2014.

LIMA, Luiz Costa. Frestas: a teorização em um país periférico. Rio de Janeiro: Contraponto, Editora PUC-Rio, 2013.

LIMA, Luiz Costa. Mímesis: desafio ao pensamento. Rio de Janeiro: Civilização Brasileira, 2001.

MATA, Anderson Luís Nunes da. Ficções: Machado de Assis, personagem de Silviano Santiago. In: DALCASTAGNE, Regina; LICARIÃ̃O, Bertonni; NAKAGOME, Patrícia (org.). Literatura e resistência. Porto Alegre: Zouk, v. 1, 2018, p. 161-171.

MOREIRAS, Alberto. The Exhaustion of Difference: the politics of Latin American cultural studies. Durham, London: Duke University Press, 2001. Doi: https://doi.org/10.1215/9780822380597.

MOTA, Lia Duarte. Um corpo de leitura. Estudos de Literatura Brasileira Contemporânea, n. 57, p. 1-9, 2019. Doi: https://doi.org/10.1590/231640185715.

MOTA, Lia Duarte. Uma poética da ferida aberta: leitura-resistência em João Gilberto Noll. In: PORTO, Ana Paula Teixeira; PEREIRA, Cilene Margarete; DEFILIPPO, Juliana Gervason (org.). Leituras da Literatura Brasileira Atual (1990-2018). Rio de Janeiro: Multifoco, v. 1, 2018, p. 164-185.

MOTTA, Leda Tenório da. Sobre a crítica literária brasileira no último meio século. Rio de Janeiro: Imago, 2002.

NODARI, Alexandre. A literatura como antropologia especulativa. Revista da Anpoll, v. 38, 2015, p. 75-85. Doi: https://doi.org/10.18309/ anp.v1i38.836.

PÉCORA, Alcir. A musa falida. Peixe Elétrico, n. 1, 2015, p. 38-66.

PÉCORA, Alcir. Impasses da literatura contemporânea. O Globo, Rio de Janeiro, 23 abr 2011. Disponível em: http://blogs.oglobo.globo. 
com/prosa/post/impasses-da-literatura-contemporanea-por-alcirpecora-376085.html. Acesso em: 23 jun. 2016.

PERRONE-MOISÉS, Leyla. Altas literaturas: escolha e valor na obra crítica de escritores modernos. São Paulo: Companhia das Letras, 2009. PUCHEU, Alberto. Dois críticos, para que servem? O amante da literatura. Rio de Janeiro: Oficina Raquel, 2010, p. 79-90. Doi: https:// doi.org/10.1590/S1517-106X2010000200005.

PUCHEU, Alberto. Pelo colorido, para além do cinzento (quase um manifesto). Pelo colorido, para além do cinzento (A literatura e seus entornos interventivos). Rio de Janeiro: Azougue, 2007. p. 10-26.

PUCHEU, Alberto. Uma tese sobre a crítica literária brasileira (por uma crítica poética). Apoesia contemporânea. Rio de Janeiro: Azougue, 2015. p. 155-182.

RESENDE, Beatriz. Estudos literários, estudos nacionais, estudos culturais: reflexões em diálogo. Semear, n. 10, 2004. Não paginado. Disponível em: http://www.letras.puc-rio.br/unidades\&nucleos/catedra/ revista/10Sem_08.html. Acesso em: 2 jul. 2016.

ROCHA, João Cezar de Castro. Considerações sobre a crítica literária. Celeuma, v. 2, n. 4, p. 24-43, 2014. Doi: https://doi.org/10.11606/ issn.2318-7875.v2i4p24-43.

ROCHA, João Cezar de Castro. Crítica literária: em busca do tempo perdido? Chapecó: Argos, 2011.

RODRIGUES, Sérgio. A crítica de mal com a literatura. Todo Prosa, 2010. Disponível em: http://todoprosa.com.br/a-critica-de-mal-com-aliteratura/. Acesso em: 5 jan. 2016.

SANTIAGO, Silviano. Uma literatura nos trópicos: ensaios sobre dependência cultural. Rio de Janeiro: Rocco, 2000.

SCHOLLHAMMER, Karl Erik. Além do visivel: o olhar da literatura. Rio de Janeiro: 7Letras, 2007.

SCHOLLHAMMER, Karl Erik. Realismo afetivo: evocar realismo além da representação. Estudos de Literatura Brasileira Contemporânea, n. 39, p. 129-148, 2012. Doi: https://doi.org/10.1590/S231640182012000100008 . 
SCHWARZ, Roberto. As ideias fora do lugar. Ao vencedor as batatas: forma literária e processo social nos inícios do romance brasileiro. 5. ed. São Paulo: Duas Cidades; Editora 34, 2000, p. 9-32. (Coleção Espírito Crítico)

STEVENS, Wallace. Imagination as Value. The Necessary Angel: Essays on Reality and the Imagination. New York: Alfred A. Knopf, 1951. p. 131-156.

SÜSSEKIND, Flora. A crítica como papel de bala. In: CORDEIRO, Sergio et al. (org.). A crítica literária brasileira em perspectiva. Cotia: Ateliê Editorial, 2013, p. 299-306. 